\title{
Sociodemographic and drug prescription pattern in patients with rheumatoid arthritis in a tertiary care teaching hospital
}

\author{
Vijoy Sankar Kairi, Sarajita Barman*
}

Department of Pharmacology, Silchar Medical College, Silchar, Assam, India

Received: 10 September 2019

Revised: 09 December 2019

Accepted: 10 December 2019

\section{*Correspondence:}

Dr. Sarajita Barman,

Email: rhinophrm@yahoo.co.in

Copyright: (c) the author(s), publisher and licensee Medip Academy. This is an open-access article distributed under the terms of the Creative Commons Attribution Non-Commercial License, which permits unrestricted non-commercial use, distribution, and reproduction in any medium, provided the original work is properly cited.

\begin{abstract}
Background: Rheumatoid arthritis (RA) is a chronic systemic autoimmune inflammatory disease that affects mainly the small joints of the hands and feet. RA is widely prevalent throughout the world.

Methods: A prospective and observational study was carried out on 44 patients for 6 months. Patients of either sex, aged between 18 to 70 years diagnosed with rheumatoid arthritis were screened and recruited in the study. Patients were diagnosed on the basis of clinical assessment and the lab parameters assessed were rheumatoid factor and antiCCP (anti-cyclic citrullinated peptide antibody). Prescriptions were analyzed for socio-demographic details and drug prescribing pattern.

Results: Out of 44 patients, $36(81.82 \%)$ were females, 8 (18.18\%) were males. Maximum occurred 19 (43.18) between 31 to 40 years of age. Out of 19 (43.18\%), females were 16 (36.36\%), males were $3(6.83 \%) .39(88.63 \%)$ were from rural and $5(11.37 \%)$ from urban area, $21(47.73 \%)$ illiterate, $15(34.09 \%)$ primary educated, $7(15.91 \%)$ secondary educated, $1(2.27 \%)$ educated above higher secondary, $4(9.08 \%)$ unemployed, $2(4.55 \%)$ students, 19 (43.18\%) housewives, 7 (15.91\%) agricultural workers, 7 (15.91\%) non-agricultural outdoor workers and $5(11.37 \%)$ non-agricultural indoor workers. Most common co-morbidity was hypertension 28 (63.63\%). Anti-CCP was positive in $38(86.36 \%)$. All of the patients $44(100 \%)$ received disease-modifying anti-rheumatic drugs (DMARDs). Majority of the patients were prescribed with triple DMARDs combination $30(68.18 \%)$.

Conclusions: We observed that female were dominant over the male with male: female ratio of 1: 4.5. Prescriptions pattern was primarily based on DMARDs.
\end{abstract}

Keywords: Rheumatoid arthritis, Housewives, DMARDs, Sulfasalazine

\section{INTRODUCTION}

Rheumatoid arthritis (RA) is a chronic multisystem disease of unknown cause. Although there are a variety of systemic manifestations the characteristic feature of RA is unabated inflammatory synovitis, usually involving peripheral joints in a symmetric distribution. The potential of synovial inflammation to cause cartilage damage and bone erosions and subsequent changes in joint integrity is the characteristic trait of the disease. Affecting around $1 \%$ of the population worldwide it is the most common autoimmune inflammatory joint disease worldwide. ${ }^{1,2}$ It has a significant negative impact on the ability to perform daily activities, including work and household tasks, and health related quality of life. ${ }^{3}$ With a prevalence of $0.75 \%$ in the Indian adult population it is one of the many chronic autoimmune diseases that predominates in women with approximately $75 \%$ of prevalent cases being female. ${ }^{4,5}$ The basis of the gender differences is not known but presumably is related to effects of the hormonal milieu on immune function. There is an inverse association between socioeconomic 
status measured by education and -occupational class and risk of RA. ${ }^{2}$

According to the American College of Rheumatology (ACR) and the European League against Rheumatism (EULAR), the current approach focuses on disease early treatment with synthetic or biological disease-modifying anti-rheumatic drugs (DMARDs) as soon as the diagnosis is completed. The recommendation is to initiate the use of synthetic DMARD while the biological DMARD is usually recommended after its failure. It is recommended during the first 3 months after the diagnosis of RA. As adjunctive therapy in the treatment of RA, symptomatic drugs that act in the control of pain and inflammation such as analgesics, nonsteroidal anti-inflammatory drugs (NSAIDs), and steroids (corticosteroids) are recommended. $^{6}$

The first Indian guidelines on management of RA were published in 2002. Since then there has been a paradigm shift in the management of RA which now aims at induction of remission and maintenance of tight control through use of conventional and biological disease modifying antirheumatoid drugs (DMARDs). The latter are more expensive and beyond the reach of majority of patients. These developments have actually posed new challenges to those practising rheumatology in a resource poor country like ours. ${ }^{7}$

Presently, studies on RA in detail regarding the sociodemographic profile are sparse in southern part of Assam, present study was undertaken to analyze the socio-demographic profile and drug prescribing pattern in patients with RA in Silchar Medical College and Hospital, Silchar. This is the only referral hospital located in southern part of Assam.

\section{METHODS}

This was a prospective observational study in the OPD of orthopaedics in SMCH, Silchar for a period of six months from June 2017 to November 2017. Patients were diagnosed on the basis of clinical assessment and the lab parameters assessed were rheumatoid factor and antiCCP (anti-cyclic citrullinated peptide antibody). Patients between 18 to 70 years of age were included. Pregnant and lactating women and patients having deranged liver and kidney function parameters were excluded. Patients having uncontrolled diabetes mellitus, congestive heart failure or having immunosuppression due to drug or disease were also excluded.

Written informed consent was taken from each participant. Socio-demographic and medication details and relevant data of lab investigations were collected using a specially designed proforma. Prescriptions of the study patients were collected and analysed. The details of medication collected from the patients included the name of the prescribed drug or drug combinations, dosage form, daily dosage, frequency, drugs prescribed by generic or brand name and all the co-prescribed drugs. The drugs prescribed for the RA were analyzed on 44 prescriptions.

The study was carried out for a period of 6 months from July 2017 to December 2017. Subject recruitment was started only after obtaining approval from the Institutional Ethical Committee (IEC) meeting held on 20/02/2017.

Data were entered in computer database and statistical analysis was done with the help of Microsoft Excel 2007.

\section{RESULTS}

Table 1 shows the gender distribution of the study population. Out of 44 rheumatoid arthritis patients, 36 $(81.82 \%)$ were females and $8(18.18 \%)$ were males. If we look at the age wise distribution of cases, most of the cases fall under the age group of 31 to 40 (43.19\%), followed by age group of 41 to 50 years $(25 \%)$ (Table 1 ).

Table 1: Distribution of patients according to sex and age group.

\begin{tabular}{|lll|}
\hline Age in years & Male $(\mathbf{n = 8})$ & Female $(\mathbf{n = 3 6 )}$ \\
\hline $\mathbf{1 8 - 3 0}$ & $\mathbf{N}(\boldsymbol{\%})$ & $\mathbf{N}(\boldsymbol{\%})$ \\
\hline $\mathbf{3 1 - 4 0}$ & $1(2.27)$ & $5(11.36)$ \\
\hline $\mathbf{4 1 - 5 0}$ & $3(6.83)$ & $16(36.36)$ \\
\hline $\mathbf{5 1 - 6 0}$ & $2(4.55)$ & $9(20.45)$ \\
\hline $\mathbf{6 1 - 7 0}$ & $2(4.55)$ & $5(11.36)$ \\
\hline
\end{tabular}

Table 2: Distribution of cases according to residence and age group

\begin{tabular}{|lll|}
\hline Age group & Rural & Urban \\
\hline $\mathbf{1 8 - 3 0}$ & $\mathbf{N}(\mathbf{\%})$ & N (\%) \\
\hline $\mathbf{3 1 - 4 0}$ & $5(11.36)$ & $1(2.27)$ \\
\hline $\mathbf{4 1 - 5 0}$ & $16(36.36)$ & $3(6.83)$ \\
\hline $\mathbf{5 1 - 6 0}$ & $10(22.73)$ & $1(2.27)$ \\
\hline $\mathbf{6 1 - 7 0}$ & $7(15.91)$ & $0(0)$ \\
\hline Total & $1(2.27)$ & $0(0)$ \\
\hline
\end{tabular}

It was seen that, out of 44 patients, 39 (88.63\%) were from rural area and $5(11.37 \%)$ were from urban area. Most rural and urban patients were from the age group $31-40$ years $(36.36 \%$ and $6.83 \%$ respectively) (Table 2 ).

According to educational status, out of 44 patients, 21 $(47.73 \%)$ were illiterate, $15(34.09 \%)$ were primary educated, $7(15.91 \%)$ were secondary educated and 1 $(2.27 \%)$ were educated above higher secondary. Out of the 21 illiterate patients, $16(36.36 \%)$ were females and 5 $(11.37 \%)$ were male patient (Table 3$)$.

Out of 44 patients $4(9.08 \%)$ were unemployed of which 3 $(6.81 \%)$ were females and $1(2.27 \%)$ were male. Along 
with that, there were $2(4.55 \%)$ students, $19(43.18 \%)$ housewives, $7(15.91 \%)$ agricultural workers, 7 (15.91\%) non-agricultural outdoor workers and $5(11.37 \%)$ nonagricultural indoor workers (Table 4).

Table 3: Distribution of cases according to educational status.

\begin{tabular}{|llllll|}
\hline Gender & Illiterate & Primary & Secondary & Higher secondary and above & Total \\
\hline Male & $\mathbf{N}(\boldsymbol{\%})$ & $\mathbf{N}(\boldsymbol{\%})$ & $\mathbf{N}(\boldsymbol{\%})$ & $\mathbf{N}(\boldsymbol{\%})$ & $\mathbf{N}(\%)$ \\
\hline Female & $5(11.37)$ & $1(2.27)$ & $1(2.27)$ & $1(2.27)$ & $8(18.18)$ \\
\hline Total & $16(36.36)$ & $14(31.82)$ & $6(13.64)$ & $0(0)$ & $36(81.82)$ \\
\hline
\end{tabular}

Table 4: Distribution of cases according to occupational status.

\begin{tabular}{|c|c|c|c|c|c|c|}
\hline \multirow[t]{2}{*}{ Gender } & Unemployed & Student & $\begin{array}{l}\text { Housewife/ } \\
\text { Homeworker }\end{array}$ & $\begin{array}{l}\text { Agricultural } \\
\text { worker }\end{array}$ & $\begin{array}{l}\text { Non-agricultural } \\
\text { outdoor worker }\end{array}$ & $\begin{array}{l}\text { Non-agricultural } \\
\text { indoor worker }\end{array}$ \\
\hline & $\mathbf{N}(\%)$ & $\mathbf{N}(\%)$ & $\mathbf{N}(\%)$ & $\mathbf{N}(\%)$ & $\mathbf{N}(\%)$ & $\mathbf{N}(\%)$ \\
\hline Male & $1(2.27)$ & 0 & 0 & $3(6.82)$ & $2(4.55)$ & $2(4.55)$ \\
\hline Female & $3(6.81)$ & $2(4.55)$ & $19(43.18)$ & $4(9.09)$ & $5(11.36)$ & $3(6.82)$ \\
\hline Total & $4(9.08)$ & $2(4.55)$ & $19(43.18)$ & $7(15.91)$ & 7 (15.91) & $5(11.37)$ \\
\hline
\end{tabular}

Table 5: Distribution of co-morbid conditions.

\begin{tabular}{|ll|}
\hline Co-morbidities & No. of patients $(\%)$ \\
\hline Hypertension & $28(63.63)$ \\
\hline Diabetes mellitus & $10(22.73)$ \\
\hline Hypothyroidism & $2(4.55)$ \\
\hline
\end{tabular}

Hypertension was observed in 28(63.63\%), diabetes mellitus in $10(22.73 \%)$ and hypothyroidism in $2(4.55 \%)$ of the cases (Table 5).
Table 6: Distribution of laboratory parameters.

\begin{tabular}{|ll|}
\hline & N $(\%)$ \\
\hline Positive RA factor & $31(70.45)$ \\
\hline Raised anti-CCP & $38(86.36)$ \\
\hline
\end{tabular}

Out of 44 patients positive serum RF was observed in 31 $(70.45 \%)$ and anti-CCP was raised in $38(86.36 \%)$ of the cases (Table 6).

Table 7: Drugs prescribed.

\begin{tabular}{|c|c|c|}
\hline Drug groups & Name of drugs & No of prescriptions (\%) \\
\hline \multirow{3}{*}{ DMARDS } & Sulfasalazine & $44(100)$ \\
\hline & Methotrexate & $40(90.9)$ \\
\hline & Hydroxychloroquine & $36(81.81)$ \\
\hline \multirow{3}{*}{ DMARDS combinations } & Sulfasalazine+methotrexate+hydroxychloroquine & $30(68.18)$ \\
\hline & Sulfasalazine+methotrexate & $9(20.46)$ \\
\hline & Sulfasalazine+hydroxychloroquine & $5(11.36)$ \\
\hline \multirow{4}{*}{ NSAIDS and analgesics } & Celecoxib & $6(40)$ \\
\hline & Naproxen & $4(26.67)$ \\
\hline & Diclofenac & $3(20)$ \\
\hline & Paracetamol & $2(13.33)$ \\
\hline \multirow{4}{*}{$\begin{array}{l}\text { Proton pump inhibitors and } \\
\text { histamine- } 2 \text { receptor antagonist } \\
25(56.82 \%)\end{array}$} & Rabeprazole & $12(48)$ \\
\hline & Pantoprazole & $6(24)$ \\
\hline & Omeprazole & $5(20)$ \\
\hline & Ranitidine & $2(8)$ \\
\hline \multirow{2}{*}{$\begin{array}{l}\text { Calcium and multivitamin } \\
8(\mathbf{1 8 . 1 8 \%})\end{array}$} & Calcium with multivitamin & $5(62.5)$ \\
\hline & Multivitamin & $3(37.5)$ \\
\hline \multirow{2}{*}{ Corticosteroids $4(9.09 \%)$} & Prednisolone & $3(75)$ \\
\hline & Dexamethasone & $1(25)$ \\
\hline
\end{tabular}

Table 7 shows the drugs that were prescribed. About 14 (31.82\%) were taking two DMARDs and 30 (68.18\%) were on three DMARDs. None of them were on biologic DMARDs. Sulfasalazine was prescribed in all cases
$(100 \%)$ followed by methotrexate $(90.9 \%)$ and hydroxycholoquine $(81.81 \%)$. Most commonly prescribed drugs following DMARDs were NSAIDs 15 (34.09\%), celecoxib being the most common NSAID prescribed. 
Corticosteroids were prescribed in $4(9.09 \%)$ of the patients.

\section{DISCUSSION}

This study revealed that prevalence of RA was more in females $36(81.82 \%)$ than males 8 (18.20\%). Similar type of studies done by Shini et al showed that females patients were $(83.46 \%)$ and males were $16.54 \% .^{8}$ A study conducted by Mittal et al., has reported that more than $80 \%$ of the RA patients were females, which is in agreement with our study. ${ }^{9}$ In this research, we observed that male to female ratio was $1: 4.5$ which was very close to 1:4 ratio observed by Aletaha et al. ${ }^{10}$ Whereas in a study conducted by Singh et al. ${ }^{11}$ Male to female ratio $(1: 8.4)$ was higher than the ratio in this study. Since rheumatoid arthritis is an auto immune disease, this female predominance is due to reasons like the influence of hormonal factors and $\mathrm{X}$ linked genes involved in pathogenesis of rheumatoid arthritis. ${ }^{12}$ Our study showed that the peak prevalence of RA was in the age group of $31-40(43.18 \%)$ followed by $41-50(25 \%)$ in both the genders. In all the age groups the female were dominant over the male in number. But, peak prevalence of RA observed by Bajraktari et al in both genders was 40-49 (32.5\% of females, $33 \%$ of males respectively). ${ }^{13}$ Present study shows that there is an increase preponderance of RA in rural area $39(88.62 \%)$. Microtrauma to musculoskeletal tissues from occupational overuse and/or misuse can pose an issue to villagers. ${ }^{14}$ In our study, the vast majority of the patients were housewives 19(43.18\%) which was similar to a study done by Kashefi et al where most of the patients were housewives $(66.4 \%)$. The higher prevalence of RA among the housewives or farmers was probably due to prolonged the duration of physical work with standing posture in the household work or agricultural field. ${ }^{15}$

Present study shows that majority of the patients were illiterate $21(47.73 \%)$. Behavioral risk factors such as smoking, diet, obesity, and a sedentary lifestyle appear to be more frequent among persons with low education. Individuals with low education are more likely to be unemployed or have higher risks of injury due to work in physically demanding jobs and greater degrees of stress. In addition, they are less likely to engage in self-care activities for RA. ${ }^{16}$ Positive serum RF was observed in 31 $(70.45 \%)$ of RA patients which was found to be similar to the study done by Bal et al $(69.2 \%) .{ }^{17}$ The anti-CCP was raised in $38(86.36 \%)$ of the patients which is almost similar to the study by Shini et al where anti-CCP was raised in $87.29 \%$ of the patients. ${ }^{8}$ In our study hypertension $28(63.63 \%)$ was the most common comorbidity followed by diabetes mellitus 10 (22.73\%) which was similar to the study conducted by Immanuel et al. $^{18}$

All the patients were on treatment with DMARDs, the most commonly prescribed being SSZ followed by MTX and HCQ. The most prescribed combination was the triple
DMARD combination of SSZ, MTX and HCQ followed by the dual combinations. None of the patients received single DMARD. Early intervention with disease specific anti-rheumatic drugs, also called second line drugs or disease-modifying antirheumatic drugs (DMARDs) is the cornerstone of treatment and, in the early stages may be able to curb or arrest the progressive synovitis and joint destruction and thereby limit disability. ${ }^{19}$ There has been increased interest in using combination DMARD therapy for patients with early RA. The principle behind combination therapy is to combine drugs with different mechanisms of action to increase efficacy, while maintaining a favourable side effect/toxicity profile, analogous to the use of combination cytotoxic treatment in oncology. ${ }^{20}$

It was observed that the most commonly prescribed drug following DMARDs was NSAIDs 15 (34.09\%) which is similar to the study done by Gurung et al, which showed that most commonly prescribed drug following DMARDs was NSAIDs $29(28.71 \%) .{ }^{21}$ Analgesics and NSAIDs are used mainly on a temporary basis until the DMARDs take effect, as well as during disease flares. ${ }^{22}$ Due to the reduction of prostaglandins production in the gastrointestinal mucosa, NSAIDs can cause gastric damage and compromise cardiovascular safety. ${ }^{23}$ In our study the most commonly prescribed gastroprotective agents were rabeprazole $12(48 \%)$ followed by Pantoprazole 6 (24\%). Calcium and multivitamin were prescribed in $8(18.18 \%)$ of the patients. In our study Prednisolone $3(75 \%)$ was the more commonly prescribed steroid The EULAR recommends the use of a low-dose corticosteroid as part of the initial treatment strategy in combination with DMARD for up to 6 months, decreasing the dose as clinically as possible. ${ }^{24}$

\section{CONCLUSION}

This study mainly focused on the socio-demographic details and treatment pattern in RA patients in southern Assam. The socio-demographic aspects of the present study showed that prevalence of rheumatoid arthritis is higher among females and between the ages of 31 and 40 years. Majority of the patients are housewives. Other socio-demographic factors are rural locality, illiteracy and low socioeconomic status. Hypertension is the most common co-morbid condition. The drug use pattern in RA is found to be primarily based on DMARDs, sulfasalazine being the most commonly used DMARD. The study of prescription pattern is an important guide for practising physicians in managing patients with RA. Future research are needed to be carried out on a larger scale to get the complete picture of the of the drug usage pattern and of the epidemiology of rheumatoid arthritis.

\section{ACKNOWLEDGEMENTS}

Authors would like to express their sincere gratitude to all respondents for their participation. 
Funding: No funding sources

Conflict of interest: None declared

Ethical approval: The study was approved by the Institutional Ethics Committee

\section{REFERENCES}

1. Prabha ML, Rani AG, Balasubramanian M, Ramya JE. Prescribing pattern and adverse drug reactions monitoring in patients with rheumatoid arthritis in a tertiary care hospital. Int J Basic Clin Pharmacol. 2016;5(3):805-9.

2. Liao PK, Alfredsson L, Karlson WE. Environmental influences on risk for rheumatoid arthritis. Curr Opin Rheumatol. 2009;21(3):279-83.

3. Singh JA, Saag KG, Bridges SL Jr, Akl EA, Bannuru RR, Sullivan MC, et al. American College of Rheumatology Guideline for the Treatment of Rheumatoid. Arthritis. Arthritis Rheumatol. 2016;68(1):1-26.

4. Dahiya A, Kalra BS, Saini A, Tekur U. Prescription pattern in patients with rheumatoid arthritis in a teaching tertiary care hospital. MAMC J Med Sci. 2016;2(1):33-7.

5. Cooper GS, Stroehla BC. The epidemiology of autoimmune diseases. Autoimmun Rev. 2003;2:11925

6. Moura MG, Lopes LC, Silva MT, Filho SB, Motta RHL, Bergamaschi C. Use of steroid and nonsteroidal anti-inflammatories in the treatment of rheumatoid arthritis. Medicine. (2018);97(41):e12658.

7. Misra R, Sharma BL, Gupta R, Pandya S, Agarwal S, Agarwal P, et al. Indian Rheumatology Association consensus statement on the management of adults with rheumatoid arthritis. Indian $\mathrm{J}$ Rheumatol. 2008;3(3):1-16.

8. Shini VK, Aboobacker S, Pahuja S, Revikumar KG, Bhasi R. Pharmacoeconomic study of DMARDs in the management of rheumatoid arthritis. Int J Pharma Sci Rev Res. 2010;5(3):148-54.

9. Mittal N, Mittal R, Sharma A, Jose V, Wanchu A, Singh S. Treatment failure with disease-modifying antirheumatic drugs in rheumatoid arthritis patients. Singapore Med J. 2012;53(8):532-6.

10. Aletaha D, Smolen JS. The rheumatoid arthritis patient in the clinic: comparing more than 1300 consecutive DMARD courses. Rheumatology. 2002;41(12):1367-74.

11. Singh AV, Malaviya AN, Kumar S. Characteristics of rheumatoid arthritis patients at first presentation to a specialized rheumatology department. Int J Res Med Sci. 2015;3(8):2073-8.

12. Kasper DL, Hauser SL, Jamesson JL, fauci AS Longo DL, Loscalzo J. Harrison's Principle of Internal Medicine. 19th Edition. USA: McGraw Hill Education; 2015.

13. Bajraktari IH, Teuta BÇ, Vjollca SM, Bajraktari H, Saiti V, Krasniqi B, et al. Demographic Features of
Patients with Rheumatoid Arthritis in Kosovo. Med Arch. 2014;68(6):407-10.

14. Handa R, Rao U.R.K, Lewis J.F.M, Rambhad G, Shiff S, Ghia CJ. Literature review of rheumatoid arthritis in India. Int J Rheumatic Dis. 2016;19:44051.

15. Kashefi S, Lee SM, Mallaysamy S, Thunga G. Demographic, clinical characteristics and drug prescription pattern in patients with rheumatoid arthritis in south Indian tertiary care hospital. Int $\mathbf{J}$ Phrm Sci. 2016;8(8):251-7.

16. Lee YH. Effect of Formal Education Level on Measurement of Rheumatoid Arthritis Disease Activity. J Rheumatic Dis. 2015;22(5):271-3.

17. Bal A, Ataman S, Bodur H, Rezvani A, Paker N, Tastekin N. Characteristics of Patients With Rheumatoid Arthritis in Turkey: Results From the Turkish League Against Rheumatism Rheumatoid Arthritis Registry. Arch Rheumatol. 2015;30(1):1622.

18. Jebastine MI, Nasmi N, Elias N, Neethu VV, Arul B. Prescription pattern of drugs used in management of rheumatoid arthritis in a tertiary care hospital: A retrospective study. Indo Am $\mathrm{J}$ Pharm Sci. 2015;2(8):1198-205.

19. Chakravarty K, McDonald H, Pullar T, Taggart A, Chalmers R, Oliver S, et al. BSR/BHPR guideline for disease-modifying anti-rheumatic drug (DMARD) therapy in consultation with the British Association of Dermatologists. Rheumatology (Oxford). 2008;47(6):924-5.

20. Suresh E, Lambert CM. Combination treatment strategies in early rheumatoid arthritis. Ann Rheum Dis. 2005;64(9):1252-56.

21. Gurung S, Babu S, Sabu S, Shibu RM, Begum R, Nanjwade BK. A study on prescribing pattern in the management of osteoarthritis and rheumatoid arthritis in the department of orthopaedics. World J Pharmacy Pharma Sci. 2016;5(4):1472-93.

22. Kumar P, Banik S. Pharmacotherapy Options in Rheumatoid Arthritis. Clin Med Insights Arthritis Musculoskelet Disord. 2013;6(6):35-43.

23. Antman EM, Bennett JS, Daugherty A, Furberg C, Roberts H, Taubert KA, et al. Use of nonsteroidal antiinflammatory drugs: an update for clinicians: a scientific statement from the American Heart Association. Circulation. 2007;115:1634-42.

24. Smolen JS, Landewe R, Breedveld FC, Buch M, Burmester G, Dougados $\mathrm{M}$, et al. EULAR recommendations for the management of rheumatoid arthritis with synthetic and biological diseasemodifying antirheumatic drugs: 2013 update. Ann Rheum Dis. 2014;73:492-509.

Cite this article as: Kairi VS, Barman S.

Sociodemographic and drug prescription pattern in patients with rheumatoid arthritis in a tertiary care teaching hospital. Int J Basic Clin Pharmacol 2020;9:96-100. 